CODEN : ASMCCO

\title{
THE IMPACT OF TOURISM DEVELOPMENT ON THE ENVIRONMENT IN CHINA
}

\author{
Jing Zhaoo, ${ }^{1,2}$, Shu-Min Li ${ }^{1}$ \\ ${ }^{1}$ School of Economic \& Management, Northwest University, 710127, Xi'an, Shaanxi, China. \\ ${ }^{2}$ School of History, Culture and Tourism, Huaiyin Normal University, 223300, Huai'an, Jiangsu, China. \\ *Corresponding Author Email: sylvan_zj@foxmail.com
}

This is an open access article distributed under the Creative Commons Attribution License, which permits unrestricted use, distribution, and reproduction in any medium, provided the original work is properly cited.

\section{ARTICLE DETAILS}

\section{Article History:}

Received 12 November 2017 Accepted 12 December 2017 Available online 1 January 2018

\begin{abstract}
Tourism is the world's largest industry. With the continuous development of tourism, the impact on the environment is constantly emerging, including both negative and positive aspects. Tourism transportation, tourist attraction and tourist hotel have negative effects on the environment, such as tourism traffic pollution, tourists' uncivilized behavior and high energy consumption of hotels. At the same time, tourism also has improved infrastructure construction and enhanced environmental awareness positive effect on the environment. To ensure the coordinated development of environment and tourism is of great significance for the realization of sustainable development. Promote the coordinated development of environment and tourism through measures such as strengthen legislation and law enforcement to reduce energy consumption, enhanced environmental protection, increase financial input, strengthen environmental protection education and constituting scientific and reasonable ecotourism programming.
\end{abstract}

\section{KEYWORDS}

China, environment, tourism, environmental protection, tourism impact.

\section{INTRODUCTION}

Tourism belongs to relatively low resource consumption and relatively small environmental destruction. It is a typical environment-friendly industry. However, there are still a lot of "non-ecological" phenomena and certain energy consumption and pollution emission, which have certain impacts on the ecological environment. Tourism has become the world's largest industry. The number of international tourists exceeded 1.2 billion in 2016. Such a large-scale tourism activity may bound to have a substantial impact on the environment. In China, the total tourism revenue in 2016 was 469 trillion yuan. soared by $13.6 \%$ compared with 2015 . According to the World Tourism Organization(WTO), in 2016, the overall contribution rate of China's tourism industry to the national economy was $11 \%$, and the overall contribution to social employment exceeded $10.26 \%$, which was basically the same as the world average. China has already become an important force in the global tourism economy.

China's competitiveness ranking moved up from 17th to 15 th, according to the Travel \& Tourism Competitiveness Report 2017 issued by the World Economic Forum [1]. The 2015 ranking involves 141 country/ economy, with 136 country/ economy in 2017.

Table 1: China's Travel \& Tourism Competitiveness Ranking (2015 2017)

\begin{tabular}{|l|l|l|}
\hline \multicolumn{1}{|c|}{ Year } & 2015 & 2017 \\
\hline Randex & & \\
\hline Score & $17 / 141$ & $15 / 136$ \\
\hline
\end{tabular}

Already endowed with exceptional natural (5th) and cultural resources (1st), China has greatly benefited from increased international openness (up 24 positions), improved ICT readiness (72nd, but up 8 positions) and further investments in its ground and tourist service infrastructure (up 9 and 10 positions respectively). China's increased prioritization of its travel and tourism industry has also supported its rise. To continue to rise in the global rankings, China could further enhance its competitiveness by creating more accommodation capacity, beyond the larger cities, a more enabling environment for doing business (92nd), and address environmental sustainability (132nd) to ensure the preservation of its unique natural resources.

Table 2: China's Travel \& Tourism Competitiveness in 2017

\begin{tabular}{|l|l|l|}
\hline Index Component & Rank & Score \\
\hline Business Environment & 92 & 4.24 \\
\hline Safety and Security & 95 & 4.99 \\
\hline Health and Hygiene & 67 & 5.42 \\
\hline Human Resources and Labour Market & 25 & 5.19 \\
\hline ICT Readiness & 64 & 4.61 \\
\hline Prioritization of Travel \& Tourism & 50 & 4.8 \\
\hline International Openness & 72 & 3.0 \\
\hline Price Competitiveness & 38 & 5.3 \\
\hline Environmental Sustainability & 132 & 3.23 \\
\hline Air Transport Infrastructure & 24 & 4.31 \\
\hline Ground and Port Infrastructure & 44 & 3.95 \\
\hline Tourist Service Infrastructure & 92 & 3.23 \\
\hline Natural Resources & 5 & 5.25 \\
\hline Cultural Resources and Business Travel & 1 & 6.94 \\
\hline
\end{tabular}

Tourism is regarded as the environmental protection industry, but in its development process, there are also a series of problems. According to the report of UNWTO, in climate changes caused by human activity, the responsibility of the global tourism industry is expected to reach $7 \%$ by the year 2050, tourist transportation, accommodation and other related activities caused by carbon dioxide emissions $1 \% \sim 3 \%$ of total emissions, and accounts for about $5 \% \sim 14 \%$ percent of man-made global warming 
[2]. The impacts of tourism activities on the ecological environment are mainly reflected in the atmosphere, water, soil, geological features, plants, animals, microbes, landscapes, etc. It is believed that tourism development has both negative and positive effects on the destination ecological environment. In order to expand tourist reception, some cities in China sacrifice their ecological environment and promote the development of tourism. Environmental problems such as haze, dust, water quality and pollution have a great correlation with the decline of China's inbound tourism market.

At present, developed countries expect China to shoulder more responsibility for protecting the environment. The Chinese government has pledged to reduce carbon dioxide emissions per unit of GDP by $40 \%$ $45 \%$ by 2020 . Obviously, China's environmental protection has many problems to be solved. Tourism must reduce environmental impact while promoting economic growth and raise the productivity of natural resources. In the late 1980 s, sustainable tourism research was carried out in the aspects of tourism policy, tourism strategy and tourism research [3]. The energy conservation and emission reduction work of China's tourism industry is of great significance to the world and China's tourism industry.

\section{NEGATIVE IMPACT OF TOURISM DEVELOPMENT ON ENVIORMENT IN CHINA}

In recent years, the rapid development of China's tourism industry has brought about a lot of negative impacts on environmental development as well as the rapid economic growth.

\subsection{Negative impact of tourism transportation on Environment}

With the rapid development of China's economy, gradually increased abundant material wealth and resident disposable income, more and more families buy cars. Tourism product continues to mature, with the development of tourism market, the market for self-driving tourism has been growing rapidly every year. In 2016, the market scale of China's self-driving tourism industry was 2244 billion yuan, and the frequency of self-driving tourists in China was 5.4 times, the average duration is 3.2 days. The per capita consumption of self-driving tourism was 376-yuan, $15.4 \%$ increase over the same period, the overnight consumption per person was 2060 yuan, $14 \%$ increase over the same period.

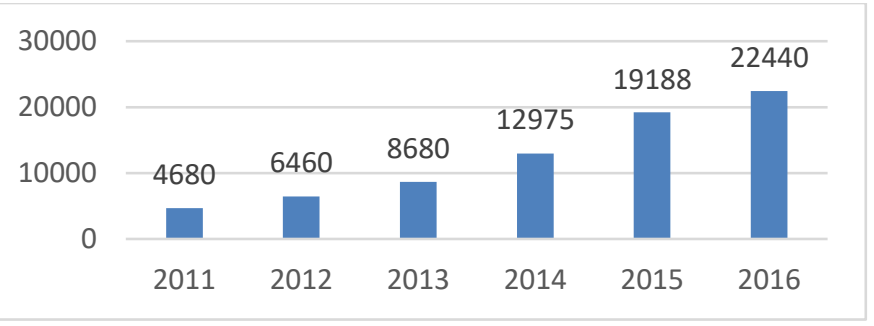

Figure 1: Self-driving tourism industry scale in China (2012-2016) (100 million yuan)

In self-driving tourism, from the travel distance, within 300 kilometers accounted for $37.5 \%, 300-500$ kilometers accounted for $14.5 \%$, more than 1000 kilometers accounted for $27.1 \%$. Self-driving tourism produce more carbon emissions than bus tourism.

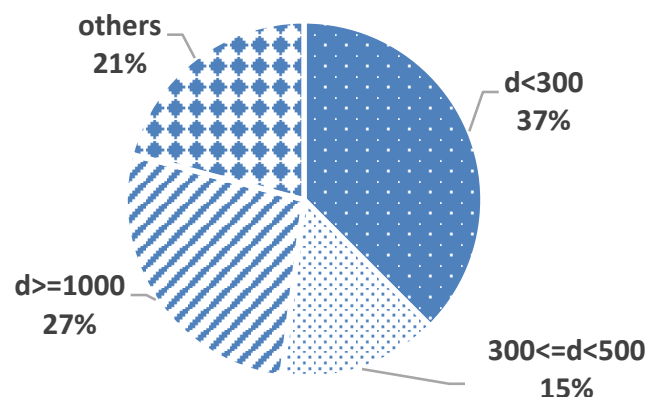

Figure 2: Travel distance distribution of self-driving tourism in China

The average daily carbon footprint of the self-driving tourists is the largest, followed by the bus tourists. With the increase of the number of self-driving tourists, energy consumption rises, automobile exhaust emissions increase, parking takes up a lot of space, and the impact on the environment is becoming more and more serious.

The trend of tourism globalization is becoming more and more obvious, and the proportion of long-distance travel is increasing. In the first half of 2017 , the number of inbound tourists was 69.5 million, and the number of outbound travel of Chinese citizens was 62.3 million.

Aviation as the preferred mode of transportation for international tourists. Air traffic tourism has the greatest impact on the environment.

\subsection{Negative impact of tourist attraction on Environment}

During the development of tourist attraction, it may affect the geological landscape and soil of the tourist attraction, and destroy the original landscape, such as the blasting stones, repairing roads, building bridges and cableway. When tourists travel in scenic spots, they affect the air, animals and plants. The impact on animals and plants is even more serious due to the large number of tourists.

With the development of tourist attraction to a certain scale, build all kinds of reception facilities, which have an impact on the existing landscape. Many tourist attractions in order to attract more tourists, establishment the hotels. Some hotels also prepared the gym, sauna, tennis, volleyball, badminton and other recreational facilities.

The number of tourists in tourist attraction exceeds the environmental capacity, and the problem of artificial, urbanization and commercialization in natural scenic areas is becoming more and more serious [4].

This extensive development mode has led to serious threats and challenges to conservation and development of some nature reserves, scenic spots, forest parks, geological parks and historical and cultural heritages [5].

\subsection{Negative impact of tourist hotel on Environment}

Tourist hotels spends more than 50 million yuan on disposable supplies cost every year. Most of the disposable products and their packaging are made of plastic. The environmental protection department needs to invest heavily to deal with it. Due to the increasing scale of the tourism industry, the energy consumption generated by tourist hotels is very impressive. The tourist hotel is responsible for bad effects on the environment, such as cleaning and discharging waste water, the waste gas discharged from the air conditioning facilities.

The energy consumption of tourist hotels is mainly used for air conditioning, lighting, hot water supply, elevator and so on. Business center, leisure center and other facilities of tourist hotels consume more energy. Indoor temperature and humidity are moderated by the demands of tourists, increases the consumption of energy.

\section{POSITIVE IMPACT OF TOURISM DEVELOPMENT ON ENVIORMENT IN CHINA}

\subsection{Improve infrastructure construction}

With the development of tourism, the tourism destination has obtained more economic income, and has enough funds to improve the infrastructure. Road construction and greening, construction of gas pipeline instead of coal cinder, in many rural areas to realize the centralized recycle of garbage and waste water. These are greatly improved the quality of life of local residents and reduce carbon emissions, beneficial impact on the environment.

The improvement of local tourism infrastructure is conducive to the tourism activities, at the same time the development of tourism provides financial support for the improvement of tourism facilities, thus forming a virtuous circle.

The tourism income can be used to protect the endangered animal and plant, improve the ecological environment of tourist attractions, repair and protection of cultural heritage scenic spot of cultural relics, and these measures have had a positive impact on the environment.

\subsection{Enhance environmental awareness}

Because of the development of tourism and the improvement of infrastructure, the local residents increase their disposable income. The local residents benefit from tourism, and they begin to protect the environment voluntarily and enhance the awareness of environmental protection. 
Local residents will consciously serve as advocate of environmental protection obligations, to promote the concept of environmental protection, stop tourists' uncivilized behaviour [6]. The Tibetan people in Bitahai Nature Reserve in Yunnan Province(China) use to stop some foreign tourists from damaging the environment and telling them the importance of environmental protection. Some of the Tibetan people who hold the horses have been able to explain the importance of environmental protection to foreign tourists in English.

The local residents will consciously clean up the garbage in scenic spots, collect the rubbish on the scenic spots or roads, and transport it to the special garbage disposal sites for treatment. When preparing a delicious meal, local residents will combine the environmental protection concept to provide healthy green fruits and vegetables for the tourists, reduce the processing links, presenting the original flavor of the food [7]

\section{MEASURES TO PROMOTE THE COORDINATED DEVELOPMENT OF TOURISM AND ENVIRONMENT IN CHINA}

\subsection{Strengthen legislation and law enforcement to reduce energy consumption}

China has promulgated a series of laws and regulations to punish the pollution water, destroy the tourism environment and discharge automobile exhaust. "Water pollution prevention and control plan for the middle and lower reaches of the Yangtze River (2011-2015 years)" was published in 2011. "Water pollution prevention action plan" was published in 2015. In 2016, the "interim measures on record management of tourist uncivilized behavior" was issued, to punish the environmental violations in Tourism. Since January 1, 2017, China has implemented the fifth stage motor vehicle emission standard, that is, "country five" standard.

China is the largest producer and consumer of energy in the world. In recent years, a series of supportive policies have been put forward to promote the development of new energy vehicles, and new energy vehicles have made significant progress. In the first nine months of 2017, the cumulative production and sales of new energy vehicles in China were 424 thousand vehicles and 398 thousand vehicles, with year-on-year growth of $40.2 \%$ and $37.7 \%$ respectively.

\subsection{Enhanced environmental protection}

Persisting in implementing the sustainable development strategy, intensifying environmental protection. Sustainable development attaches great importance to environmental protection and environmental protection as one of its most basic aims [8]. Environmental protection is an important distinction between sustainable development and traditional development.

The State Council approved the establishment of 18 national nature reserves. The 446 National Nature Reserve of human activities to carry out remote monitoring, carry out Biodiversity Observation pilot, established by birds, amphibians, mammals, animal, butterfly as indicator taxa observed area of more than 400. Promote marine ecological restoration, implement 18 "Blue Bay" project and 10 "ecological islands and reefs" project. The central government allocated 6 billion yuan to promote the comprehensive improvement of rural environment.

Since 2007, China's forest area has been increasing. In 2015, the forest area has reached 2083213 square kilometers, accounting for $22.19 \%$ of the total land area.

Table 3: Analysis of forest area of China (2007 2015)

\begin{tabular}{|l|l|l|}
\hline Year & Forest area (sq. km) & (Percentage of land area) \\
\hline 2007 & 1960704.6 & 20.88 \\
\hline 2008 & 1975837 & 21.05 \\
\hline 2009 & 1990970 & 21.21 \\
\hline 2010 & 2006103 & 21.37 \\
\hline 2011 & 2021525 & 21.53 \\
\hline 2012 & 2036947 & 21.70 \\
\hline 2013 & 2052369 & 21.86 \\
\hline 2014 & 2067791 & 22.03 \\
\hline 2015 & 2083213 & 22.19 \\
\hline
\end{tabular}

In China, the grassland area was nearly 400 million hectares, accounting for $41.7 \%$ of the total land area. There are 2,750 natural reserves of various types and levels, of which the land area accounts for $14.88 \%$ of the land area. There are 446 national nature reserves, of which the land area.

4.3 Increase financial input
In environmental protection investment, the government financial input has a clear policy guidance and exemplary significance, private sector investment in environmental protection often depends on the government fiscal expenditure level and strength, therefore, it is very important to carry out environmental protection expenditure for environmental protection work. Through the government's financial input, it can create favorable conditions and guide the large amount of social funds into the field of environmental protection. Government financial support is also facilitating the establishment of a regulatory system for environmental protection and ensure that all parties perform their duties according to law. In addition, the fiscal expenditure of environmental protection can be adjusted according to local development differences and its own limitation, focusing on balancing regional differences.

The Chinese government has continuously increased investment in environmental governance. The special funds for the prevention and control of atmospheric, water and soil in 2016 were 11.2 billion yuan,14 billion yuan, 9.1 billion yuan respectively. At the same time, the government and social capital cooperation (PPP) play a leading role in the demonstration project, with more than 630 projects in the field of ecoenvironmental protection and more than 650 billion yuan in total investment.

Fiscal transfer payment of key ecological functional areas will be paid with a scale of 57 billion yuan, the subsidy covers 725 key ecological counties.

\subsection{Strengthen environmental protection education}

Strengthen environmental protection education, raise the environmental awareness, improve the environmental protection ability. In order to realize the sustainable tourism, needs to all-round improve the environmental protection consciousness [9]. Tourist spots, travel agencies, tourist hotel and tourists are the main body of the implementation of sustainable tourism, enhance environmental awareness, conducive to the development of sustainable tourism.

For tourism practitioners, vocational training needs to carry out different levels of tourism ecological environment protection, the establishment of training system, master the relevant laws and regulations and policies, and strive to improve the quality of their ecological protection. Through the television, newspapers and Internet to carry out abundant and diversified publicity activities to popularize knowledge of environmental science, enhance the protection and publicity of eco-environmental protection in scenic spots. To improve the environmental awareness of tourists and operators, actively participate in environmental protection activities and develop green and environmental tourism consumption habits. Strengthen the education of environmental protection for residents, to help residents understand the operation mechanism of human land relationship system to care for the natural environment fundamentally, is conducive to the environmental management and the sustainable development of tourism.

\subsection{Constituting scientific and reasonable ecotourism programming}

It is necessary to establish a scientific tourism ecological programming, which is conducive to the establishment of a good tourism ecological environment, and to ensure the consistency of scientific planning, there is no planning conflict. Tourism development in ecological vulnerable zone must be a feasible way for environment improvement and ecology development if programmed properly and managed scientifically.

Programming should be advocated in tourism enterprises make full use of renewable energy, such as solar energy, hydropower, wind energy, geothermal energy, biomass energy, etc. Adopt energy saving equipment and technology, such as temperature control technology, energy-saving wall materials, energy-saving doors and windows and other energy-saving materials. In production process should save raw materials and energy, simplifying the commodity packaging, choose the natural materials. Tourism hotel provides the green room to reduce the number of wash bedding. Recycling of guest room waste and office waste after environmental protection treatment.

Ensure that the construction of tourist facilities is coordinated with the natural landscape, to formulate appropriate tourist flow, and to avoid the destruction of natural ecological system due to improper design of tourist routes [10]. With the concept of low carbon economy and industrial ecology, tourism development should be prohibited in some important and sensitive ecological areas. Programming should give priority to developing low-carbon tourism projects, such as cycling, fishing and other tourism activities, and vigorously develop tourism activities such as tourism education activities with low intensity of resources and energy consumption [11]. 


\section{CONCLUSION}

Tourism has a very important position and role in China, which has made outstanding contributions to the promotion of economic development, at the same time, must protect the environment and lay the foundation for sustainable development. Promote the benign development of tourism ecological environment, change the traditional tourism mode that consumes tourism resources and destroy tourism ecological environment, establish a new mode of low carbon, ecological development.

Try to eliminate the negative impact of tourism development on the environment, tourism enterprises to implement cleaner production, reduce waste of material and energy, recycling waste, minimizing pollutant emissions. Actively promote the positive impact of tourism development on the environment and improve the environmental awareness of tourists through education training, and eliminate the uncivilized behavior of destroying the environment in tourism activities.

Establishing the harmonious symbiosis relationship between tourism development and the ecological environment. Tourism uses the ecological environment and tourism resources to develop, and the tourism revenue is used for the ecological environment construction, realizing the sustainable utilization of resources.

\section{ACKNOWLEDGEMENTS}

This research was supported by the key project of National Social Science Foundation: Research on the tourism cooperation basis and path of The Silk Road Economic Belt(No. 14AJY025), Major bidding project of key research base of Humanities and social sciences of Ministry of Education: Research on the coordinated development of the cultural heritage protection and heritage sites in the western region (No.12JJD790018),and support program for young outstanding talent of Huaiyin Normal University: Research on the development and design of water culture tourism products in Huai'an (No.13HSQNS15). The authors also wish to thank the editor and the reviewer for their valuable comments.

\section{REFERENCES}

[1] WEF. 2017. Travel \& Tourism Competitiveness Report 2017. World Economic Forum.
[2] Scott, D., Amelung, B., Becken, S., Ceron, J P., Dubois, G., Gossling, S., Peeters, P., Simpson, M.C. 2008. UNWTO, and UNEP: Climate Change and Tourism: Responding to Global Challenges [R]. Madrid, 13-16.

[3] Budeanu, A., Miller, G., Moscardo, G., Ooi, C.S. 2016. Sustainable tourism, progress, challenges and opportunities: an introduction. Journal of Cleaner Production, 111 (5), 285-294.

[4] Dumitru, T. 2012. The Impact of Tourism Development on Urban Environment. Studies in Business and Economics, 7 (3), 160-164.

[5] Fan, Z.Y., Zhong, S., Zhang, W. 2012. Harmonious tourism environment and tourists perception: an empirical study of mountain-type world cultural heritage sites in China. Journal of Service Science and Management, 5 (1), 95-100.

[6] Tang, Z. 2015. An integrated approach to evaluating the coupling coordination between tourism and the environment. Tourism Management, 46 (1), 11-19.

[7] Jeoushyan, H., Liu, C.H., Shengfang, C., Yin, Y.S., Changyen, T. 2014. Developing a novel hybrid model for industrial environment analysis: a study of the gourmet and tourism industry in Taiwan. Asia Pacific Journal of Tourism Research, 19 (9), 1044-1069.

[8] Carson, L., Jenkins. 2010. Tourism Development and the Environment: Beyond Sustainability. Annals of Tourism Research, 37 (4), 1194-1196.

[9] Marsiglio, S. 2015. Economic growth and environment: tourism as a trigger for green growth. Tourism Economics, 21 (1), 183-204.

[10] Hjalager, A.M. 1996. Tourism and the environment: the innovation connection. Journal of Sustainable Tourism, 4 (4), 201-218.

[11] Shiaty, R.E., Taalab, M., Osama, I. 2016. Evaluating the Performance of the Outdoor Spaces in Healing Eco-Tourism. Procedia Environmental Sciences, 34, 461-473. 